\title{
RISIKO K3 PADA PELAKSANAAN KONSTRUKSI BANGUNAN GEDUNG SWASTA
}

\author{
Ni Kadek Sri Ebtha Yuni1 ${ }^{1)}$, I Nyoman Suardika ${ }^{1)}$, dan I Wayan Sudiasa ${ }^{1)}$ \\ 1) Jurusan Teknik Sipil, Politeknik Negeri Bali, Badung, Bali \\ ebthayuni@pnb.ac.id
}

\begin{abstract}
Project risks sourced from the environment, planning, financial, technical, humane, criminal, and safety. The purpose of this study to identify the safety and health risks of building construction on structural and architectural work, determine the value of risk based on the results of identification, determine risk control based on the hierarchy of risk control. This research was conducted on a private construction project on structural and architectural work. The method used is interviews and surveys. Surveys were conducted to obtain risk identification, and interviews to respondents. There were 28 identified risks, 11 risks were in the mild category and 17 were moderate risks. This risks are controlled by tool box meetings, managing work positions, placement of materials and tools, installing signs, work permits, using helmets, shoes, safety belts, gloves, and masks.
\end{abstract}

Keywords: construction projects, occupational health and safety, project risks

\begin{abstract}
ABSTRAK
Risiko proyek bisa bersumber dari lingkungan, perencanaan, keuangan, teknis, manusiawi, kriminal dan keselamatan. Tujuan penelitian ini adalah mengidentifikasi risiko keselamatan dan kesehatan kerja konstruksi bangunan gedung pada pekerjaan struktur dan arsitektur, menentukan nilai risiko berdasarkan hasil identifikasi, menentukan pengendalian terhadap risiko berdasarkan hirarki pengendalian risiko. Penelitian ini dilakukan pada proyek konstruksi swasta pada pekerjaan struktur dan arsitektur. Metode yang digunakan adalah wawancara dan survey lapangan. Survey lapangan dilakukan untuk memperoleh identifikasi risiko K3, dan wawancara untuk memperoleh pendapat responden dalam menentukan tindakan mitigasi risiko. Terdapat 28 risiko yang teridentifikasi, berada pada kategori ringan sebanyak 11 risiko dan sedang 17 risiko. Risiko-risiko tersebut dikendalikan dengan TBM (tools box meeting), APK (mengatur posisi kerja, penempatan material dan alat, pemasangan rambu-rambu), mengajukan ijin bekerja, menggunakan APD (helm, sepatu, safty belt, sarung tangan, dan masker).
\end{abstract}

Kata kunci: proyek konstruksi, K3, risiko proyek 


\section{PENDAHULUAN}

Salah satu industri yang memiliki risiko kecelakaan tinggi adalah jasa konstruksi, karena dianggap berbahaya dan dapat mengancam nyawa seseorang. Saat ini setiap pelaksanaan konstruksi diwajibkan melaksanakan K3 (Keselamatan dan Kesehatan Kerja), namun masih belum maksimal. Konstruksi bangunan gedung memiliki pekerjaan yang kompleks dibandingkan konstruksi lainnya. Bangunan gedung terdiri dari kelompok pekerjaan struktur, arsitektur, mekanikal dan elektrikal, plumbing, interior, landscape, dan pekerjaan tambahan lainnya.

Berdasarkan penelitian Setiawan, (2014) jumlah kecelakaan kerja konstruksi yang paling sering terjadi dari tahun 2005 sampai tahun 2015 adalah terjatuh, tersengat listrik dan tertimpa. Penelitian Sari (2016) dan Abryandoko (2018) memperoleh risiko $\mathrm{K} 3$ berupa tanah longsor, terkena benda tajam, terjatuh dari tempat tinggi, dan tersengat aliran listrik. Risiko lain berupa tenaga kerja yang mengalami sakit akibat kerja berupa gangguan sistem pernafasan (Purba et al., 2015). Risiko paling fatal adalah terjadinya kematian (Astiti, 2015). Pada pekerjaan skafolding memiliki 40 potensi bahaya dengan kategori risiko tinggi yang perlu mendapat penanganan (Persada, 2015).

Penelitian ini menganalisis pekerjaan struktur dan arsitektur. Langkah pertama diawali dengan melakukan observasi lapangan untuk melihat kemungkinan risiko yang terjadi. Selanjutnya melakukan wawancara kepada responden yang terpilih untuk memperoleh data identifikasi risiko yang mungkin terjadi pada saat pelaksanaan pekerjaan. Risiko-risiko yang teridentifikasi selanjutnya diberikan penilaian untuk menentukan risiko yang paling sering terjadi. Tahap terakhir adalah menentukan mitigasi atau pengendalian risiko berdasarkan hirarki pengendalian risiko.

\section{KAJIAN PUSTAKA}

\subsection{Manajemen Risiko}

Risiko proyek merupakan suatu kejadian yang tidak pasti atau berpeluang terjadi, dan mempengaruhi pelaksanaan proyek. Ketidakpastian akibat aktivitas manusia/teknologi dapat dikurangi dengan menggali lebih banyak informasi dan menerapkan model yang lebih baik. Manajemen risiko dilakukan pada setiap tahapan proyek (Husen, 2009).

\subsection{Identifikasi Risiko}

Identifikasi risiko dilakukan untuk mengumpulkan risiko-risiko yang 
kemungkinan bisa terjadi dalam suatu pelaksanaan pekerjaan. Risiko dapat dikenali berdasarkan sumbernya, kejadian dan akibat yang ditimbulkan. Dalam manajemen risiko, diawali dengan mengadakan identifikasi risiko untuk menguraikan dengan rinci jenis risiko yang mungkin terjadi dari kegiatan yang akan atau sedang dilakukan (Norken, 2015). Tahapan ini juga memberikan informasi dengan detail tentang potensi bahaya dan konsekuensinya.

\subsection{Penilaian Risiko (Risk Assessment)}

Penilaian risiko berdasarkan PERMEN PU No. 05-PRT-M-2014 nilai kekerapan terjadinya risiko $\mathrm{K} 3$ konstruksi yaitu nilai 1 (satu) jarang terjadi dalam kegiatan konstruksi, nilai 2 (dua) kadangkadang terjadi dalam kegiatan konstruksi, nilai 3 (tiga) sering terjadi dalam kegiatan konstruksi. Nilai keparahan yaitu 1 (ringan), 2 (sedang), 3 (berat).

Hazzard identification and risk
assessment adalah metode
mengidentifikasi bahaya melalui penilaian
dan matrik risiko (Susihono, 2013).

\subsection{Pengendalian Risiko}

Pengendalian risiko dilakukan dengan tujuan menentukan tindakan untuk mengurangi akibat risiko yang telah diidentifikasi. Selain itu, pengendalian dilakukan sampai batas yang dapat diterima, walaupun tidak sepenuhnya dapat dihilangkan. Identifikasi tindakan pengendalian ini dilakukan dengan hirarki pengendalian risiko, yaitu eliminasi, substitusi, rekayasa teknik, pengendalian administrasi, dan penggunaan alat pelindung diri.

1. Eliminasi merupakan peniadaan kondisi berbahaya.

2. Substitusi merupakan penggantian kondisi dan tindakan berbahaya, dengan yang lebih aman dan sehat.

3. Rekayasa merupakan penggunakan teknologi dan metode kerja yang dapat meminimalisir risiko.

4. Administratif merupakan penggunaan prosedur ijin kerja yang terkordinasi.

5. APD merupakan penggunaan alat pelindung diri yang baik dan tepat, untuk mengurangi terpaparnya oleh bahaya dan risiko.

Selain melalui hirarki pengendalian risiko, pengendalian juga bisa melalui kegiatan pendidikan dan pelatihan, serta motivasi, evaluasi melalui audit, dan penegakan hokum, safety induction, safety talk, training (Sucita, 2011). 


\section{METODE PENELITIAN}

\subsection{Rancangan Penelitian}

Penelitian ini dilakukan pada proyek konstruksi gedung swasta di Kabupaten Badung. Proyek yang dipilih adalah 2 buah yaitu pembangunan hotel yang berada di kawasan Nusa Dua dan Jimbaran yang dilaksanakan pada tahun 2019-2020. Pemilihan objek penelitian ini berdasarkan skup pekerjaan yang dikerjakan, dan tingkat kesulitannya. Pada penelitian ini mengkaji proyek yang sedang mengerjakan pekerjaan struktur dan arsitektur.

Penelitian dengan menggunakan metoda deskriptif kualitatif dan kuantitatif. Kualitatif berupa identifikasi risiko dan menentukan tindakan mitigasinya. Sementara kuantitatif berupa penilaian terhadap risiko yang teridentifikasi. Metoda pengumpulan data dilakukan dengan observasi, wawancara dan penyebaran kuesioner kepada pihak proyek yang berpengalaman di bidangnya, yang bertujuan mendapatkan opini dari responden mengenai risiko keselamatan kerja pada tahap pelaksanaan proyek.

Identifikasi risiko diperoleh melalui hasil observasi melihat kondisi lapangan dan menentukan jenis risiko yang mungkin terjadi. Identifikasi juga diperoleh melalui wawancara dengan responden yang terpilih. Penilaian risiko diawali dengan menyusun semua jenis risiko yang teridentifikasi, kemudian disusun kuesioner untuk menentukan penilaian dan mitigasi risiko. Berdasarkan hasil dari kuesioner dilakukan rekapitulasi terhadap penilaian risiko berdasarkan jawaban responden. Penilaian risiko merupakan skala frekuensi dikalikan dengan skala konsekuensi. Kategori penilaian risiko berdasarkan PERMEN PU No. 05-PRT-M2014, tingkat risiko rendah apabila frekuensi dikalikan konsekuensi adalah 1 dan 2. Risiko sedang dengan nilai 3 dan 4 . Risiko tinggi dengan nilai 6 sampai 9.

\subsection{Penentuan Sumber Data}

Data yang digunakan yaitu data primer dan data sekunder. Data primer merupakan hasil observasi, wawancara, dan penyebaran kuesioner dengan pihakpihak yang berpengalaman. Wawancara bersifat tak terstruktur, yaitu dengan bertanya langsung kepada pihak yang dituju dengan jumlah responden adalah 25 orang, Responden yang dipilih adalah berupa purposive sampling atau sample yang terpilih. Dalam penelitian ini yang menjadi responden adalah project manager, site engineering, engineer, supervisor, dan MK. Hasil dari wawancara ini berupa identifikasi risiko yang terjadi pada pelaksanaan pekerjaan terkait 
keselamatan dan kesehatan kerja pada tahap pelaksanaan proyek. Observasi dilakukan dengan meninjau langsung kondisi lapangan, menganalisis risiko yang mungkin terjadi dengan membandingkan gambar dan item pekerjaan. Hasil kuesioner digunakan untuk menentukan penilaian dan mitigasi risiko. Data sekunder berupa kajian terhadap jurnal, studi literatur, laporan-laporan yang telah dilaksanakan, sebagai gambaran dalam melakukan identifikasi awal risiko.

\section{HASIL DAN PEMBAHASAN}

\subsection{Identifikasi Risiko K3}

Risiko K3 yang dianalisis dalam penelitian ini adalah pada pekerjaan Struktur dan Arsitektur proyek bangunan Gedung. Adapun identifikasi risiko seperti Tabel 1. Berdasarkan Tabel 1 diperoleh 18 risiko yang bersumber dari pekerjaan struktur dan 10 risiko bersumber dari pekerjaan arsitektur.

\subsection{Penilaian Risiko K3}

Untuk memperoleh penilaian risiko dari responden diawali dengan pengujian validitas dan reliabilitas kuesioner. Adapun hasil penilaian risiko ditunjukkan dalam Tabel 2. Berdasarkan Tabel 2, penerimaan risiko diperoleh dua kategori yaitu rendah (nilai 2) sebanyak 11 risiko. Kategori sedang (nilai 3 dan 4) sebanyak 17 risiko.
Tabel 1. Identifikasi Risiko K3

\begin{tabular}{cl}
\hline No & \multicolumn{1}{c}{ Identifikasi Risiko } \\
\hline A. Pekerjaan Struktur \\
1 & Galian longsor \\
2 & Terperosok ke lubang galian \\
3 & Tertimbun akibat urugan \\
4 & Terjatuh saat loading unloading \\
5 & Dehidrasi bekerja di siang hari \\
6 & Terjepit oleh besi \\
7 & Terpotong barbender/ bar cutter \\
8 & Tertusuk besi \\
9 & Tertimpa besi \\
10 & Tersengat listrik \\
11 & Tertimpa beton \\
12 & Terpapar bahan kimia \\
13 & Tertimbun limestone \\
14 & Tergilas alat pemadat \\
15 & Tertabrak alat berat \\
16 & Terjepit bekisting/ sklafolding \\
17 & Tertimpa bekisting/ skafolding \\
18 & Tertusuk paku \\
B. Pekerjaan Arsitektur \\
1 & Terjepit bata \\
2 & Terjatuh dari ketinggian \\
3 & Tertimpa spesi \\
4 & Terpapar bahan kimia \\
5 & Terjepit pintu/ jendela \\
6 & Tertimpa pintu/ jendela \\
7 & Tersengat listrik \\
8 & Terpotong gerinda \\
9 & Terjepit rangka baja \\
10 & Tertusuk rangka baja \\
\hline &
\end{tabular}

\subsection{Pengendalian Risiko K3}

Semua risiko yang teridentifikasi dan dinilai dilakukan pengendalian. Adapun diagram penilaian risiko dengan kategori rendah dan sedang adalah sebagai berikut (Gambar 1):

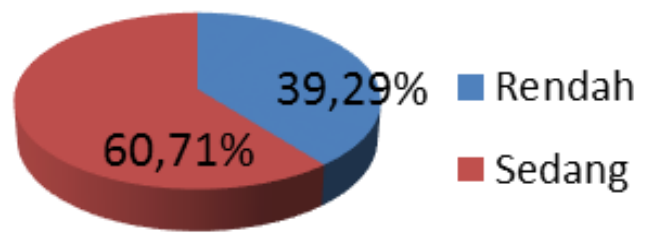

Gambar 1. Persentase Penilaian Risiko 
Tabel 2. Penilaian Risiko K3

\begin{tabular}{|c|c|c|}
\hline No & Identifikasi Risiko & $\begin{array}{l}\text { Nilai } \\
\text { Risiko }\end{array}$ \\
\hline \multicolumn{3}{|c|}{ A. Pekerjaan Struktur } \\
\hline 1 & Galian longsor & 4 \\
\hline 2 & Terperosok ke lubang galian & 4 \\
\hline 3 & Tertimbun akibat urugan & 2 \\
\hline 4 & Terjatuh saat loading unloading & 2 \\
\hline 5 & Dehidrasi bekerja di siang hari & 4 \\
\hline 6 & Terjepit oleh besi & 2 \\
\hline 7 & Terpotong barbender/ bar cutter & 3 \\
\hline 8 & Tertusuk besi & 2 \\
\hline 9 & Tertimpa besi & 4 \\
\hline 10 & Tersengat listrik & 3 \\
\hline 11 & Tertimpa beton & 4 \\
\hline 12 & Terpapar bahan kimia & 3 \\
\hline 13 & Tertimbun limestone & 2 \\
\hline 14 & Tergilas alat pemadat & 3 \\
\hline 15 & Tertabrak alat berat & 3 \\
\hline 16 & Terjepit bekisting/ sklafolding & 2 \\
\hline 17 & Tertimpa bekisting/ skafolding & 4 \\
\hline 18 & Tertusuk paku & 2 \\
\hline \multicolumn{3}{|c|}{ B. Pekerjaan Arsitektur } \\
\hline 1 & Terjepit bata & 2 \\
\hline 2 & Terjatuh dari ketinggian & 3 \\
\hline 3 & Tertimpa spesi & 4 \\
\hline 4 & Terpapar bahan kimia & 3 \\
\hline 5 & Terjepit pintu/ jendela & 4 \\
\hline 6 & Tertimpa pintu/ jendela & 2 \\
\hline 7 & Tersengat listrik & 3 \\
\hline 8 & Terpotong gerinda & 3 \\
\hline 9 & Terjepit rangka baja & 2 \\
\hline 10 & Tertusuk rangka baja & 2 \\
\hline
\end{tabular}

Secara umum pengendalian risiko berdasarkan risiko yang teridentifikasi dapat dilakukan dengan TBM (tools box meeting), APK (alat pelindung kerja), membuat ijin kerja, penggunaan APD (alat pelindung diri). Pengendalian risiko dilakukan berdasarkan tingkat penerimaan risiko. Berikut Tabel 3 tentang pengendalian risiko yang teridentifikasi:
Tabel 3. Pengendalian Risiko

\begin{tabular}{|c|c|}
\hline Risiko & Pengendalian Risiko \\
\hline $\begin{array}{l}\text { Tergilas } \\
\text { alat } \\
\text { pemadat }\end{array}$ & $\begin{array}{l}\text { APK (penempatan alat, memasang } \\
\text { rambu), Rekayasa (metode kerja } \\
\text { yang sesuai, operator } \\
\text { bersertifikat), mengajukan ijin } \\
\text { bekerja kepada pengawas }\end{array}$ \\
\hline $\begin{array}{l}\text { Tertabrak } \\
\text { alat berat }\end{array}$ & $\begin{array}{l}\text { APK (penempatan alat, memasang } \\
\text { rambu, operator bersertifikat, } \\
\text { pengaturan lalu lintas), } \\
\text { mengajukan ijin bekerja kepada } \\
\text { pengawas }\end{array}$ \\
\hline $\begin{array}{l}\text { Terpotong } \\
\text { barbenderl } \\
\text { bar cutter }\end{array}$ & $\begin{array}{l}\text { Rekayasa (menata meja kerja dan } \\
\text { lingkungan kerja, penerangan } \\
\text { yang baik, APD (menggunakan } \\
\text { sarung tangan) }\end{array}$ \\
\hline $\begin{array}{l}\text { Tersengat } \\
\text { listrik }\end{array}$ & $\begin{array}{l}\text { Rekayasa (menata jalur listrik, } \\
\text { penerangan yang baik, memantau } \\
\text { instalasi listrik dan alat), APK } \\
\text { (memasang rambu) APD } \\
\text { (menggunakan sepatu kerja) }\end{array}$ \\
\hline $\begin{array}{l}\text { Terjatuh } \\
\text { dari } \\
\text { ketinggian }\end{array}$ & $\begin{array}{l}\text { Rekayasa (metode kerja yang } \\
\text { baik, pemasangan scaffolding } \\
\text { yang kokoh), mengajukan ijin } \\
\text { bekerja, APD (menggunakan } \\
\text { safety belt, helm kerja, sepatu dan } \\
\text { sarung tangan) }\end{array}$ \\
\hline $\begin{array}{l}\text { Terpapar } \\
\text { bahan } \\
\text { kimia }\end{array}$ & $\begin{array}{l}\text { APD (menggunakan masker, } \\
\text { sarung tangan, pakian tertutup, } \\
\text { sepatu kerja) }\end{array}$ \\
\hline
\end{tabular}

\section{SIMPULAN DAN SARAN}

\subsection{Simpulan}

1. Risiko keselamatan dan kesehatan kerja konstruksi bangunan gedung pada tahap pekerjaan struktur dan arsitektur teridentifikasi sebanyak 28 risiko.

2. Kategori risiko yang teridentifikasi adalah rendah dengan jumlah 11 risiko dan sedang 17 risiko.

3. Tindakan pengendalian yang dilakukan pada risiko yang 
teridentifikasi adalah melakukan toolsbox meeting, membuat alat pelindung kerja, melakukan ijin kerja dan menyediakan alat pelindung diri.

\subsection{Saran}

1. Semua Risiko K3 sebaiknya mendapat perhatian bagi stakeholder proyek dengan lebih meningkatkan penerapan K3.

2. Penelitian ini dapat dikembangkan dengan meninjau paket pekerjaan lain yaitu Mekanical, Electical, Plumbing, Interior, Hardscape, Landscape pada pembangunan gedung lainnya.

\section{DAFTAR PUSTAKA}

Abryandoko, E. W. (2018). Penilaian Risiko Keselamatan dan Kesehatan Kerja dengan Menggunakan Metode HIRADC dan Safety Policy. Universitas Bojonegoro.

Anonim. (2014). Peraturan Menteri PU No.05/PRT-M/2014 tentang Pedoman Sistem Manajemen Keselamatan dan Kesehatan Kerja (SMK3) Konstruksi Bidang Banguan Umum. Lembaran Negara RI. Jakarta: Sekreteriat Negara Republik Indonesia.

Astiti, N. P. M., Norken, N., \& Purbawijaya, I B. N. (2015). Analisis Risiko Pelaksanaan Pembangunan Jalan Tol Benoa-Bandara-Nusa Dua. Jurnal Spektran, 3 (2).
Brahmatariguna, I. A. (2016). Hubungan Kompetensi Project Manager Terhadap Keberhasilan Proyek Konstruksi Gedung. Jurnal Spektran, $4(2)$.

Djatmiko. (2016). Keselamatan dan Kesehatan Kerja, Edisi 1. Yongyakarta: Penerbit Deepublish.

Husen, A. (2011). Manajemen Proyek, Perencanaan, Penjadwalan, \& Pengendalian Proyek. Yogyakarta: Andi.

Latupeirissa, J. E. (2016). Metode Perencanaan Evaluasi dan Pengendalian Pelaksanaan Proyek, Edisi 1. Yogyakarta: Andi.

Nurhayati. (2010). Manajemen Proyek Konstruksi, Cetakan pertama. Yogyakarta: Andi Offset.

Norken, I N. (2015). Pengantar Analisis Manajemen Risiko Proyek Konstruksi. Denpasar: Udayana University Press.

Persada, Y. B. (2015). Risk Asesment K3 pada Proses Pengoperasinalan Skafolding pada Proyek Apartemen PT X di Surabaya. The Indonesian Journal of Occupational Safety and Health, 4 (2).

Purba, E. A., Kurnia B., M. A., Hatmoko, J. U. D., \& Kistiani, F. (2015. Analisa Manajemen Risiko pada Proyek PDAM Semarang (Studi Kasus: Proyek Pemipaan IPA Kaligarang Semarang Barat). Jurnal Karya Teknik Sipil, 4(4), 274-282.

Sari. N. (2016). Manajemen Risiko Keselamatan dan Kesehatan Kerja pada Pekerjaan Konstruksi. Universitas Tanjungpura.

Setiawan, P. F. (2014). Manajemen Risiko Proyek Vale di PT. Multipanel Intermitra Mandiri. Journal uajy.

Sucita. I. K., \& Broto. A. B. (2011). 
Identifikasi dan Penanganan Risiko K3 pada Proyek Konstruksi Gedung. Politeknologi, 10 (1).

Susihono, W., \& Rini, F. A. (2013). Penerapan Sistem Manajemen Keselamatan dan Kesehatan Kerja (K3) dan Identifikasi Potensi Bahaya Kerja (Studi Kasus di PT. LTX Kota Cilegon- Banten). Jurnal Spektrum Industri, 11(2), 117-242. 